OPEN ACCESS

Edited by:

Craig N. Jenne,

University of Calgary, Canada

Reviewed by:

John W. Semple,

Lund University, Sweden

Samantha J. Montague,

Australian National University, Australia

*Correspondence:

Braedon McDonald bamcdona@ucalgary.ca

Specialty section:

This article was submitted to

Molecular Innate Immunity,

a section of the journal

Frontiers in Immunology

Received: 15 April 2019 Accepted: 25 September 2019

Published: 11 October 2019

Citation: McDonald B and Dunbar M (2019)

Platelets and Intravascular Immunity: Guardians of the Vascular Space During Bloodstream Infections and Sepsis. Front. Immunol. 10:2400 doi: 10.3389/fimmu.2019.02400

\section{Platelets and Intravascular Immunity: Guardians of the Vascular Space During Bloodstream Infections and Sepsis}

\author{
Braedon McDonald ${ }^{1 *}$ and Mary Dunbar ${ }^{2}$ \\ ${ }^{1}$ Department of Critical Care Medicine, Snyder Institute for Chronic Diseases, Cumming School of Medicine, University of \\ Calgary, Calgary, AB, Canada, ${ }^{2}$ Department of Pediatrics, Alberta Children's Hospital Research Institute, Cumming School of \\ Medicine, University of Calgary, Calgary, AB, Canada
}

Despite their humble origins as anuclear fragments of megakaryocytes, platelets have emerged as versatile mediators of thrombosis and immunity. The diverse spectrum of platelet functions are on full display during the host response to severe infection and sepsis, with platelets taking center-stage in the intravascular immune response to blood-borne pathogens. Platelets are endowed with a comprehensive armamentarium of pathogen detection systems that enable them to function as sentinels in the bloodstream for rapid identification of microbial invasion. Through both autonomous anti-microbial effector functions and collaborations with other innate immune cells, platelets orchestrate a complex intravascular immune defense system that protects against bacterial dissemination. As with any powerful immune defense system, dysregulation of platelet-mediated intravascular immunity can lead to profound collateral damage to host cells and tissues, resulting in sepsis-associated organ dysfunction. In this article, the cellular and molecular contributions of platelets to intravascular immune defenses in sepsis will be reviewed, including the roles of platelets in surveillance of the microcirculation and elicitation of protective anti-bacterial responses. Mechanisms of platelet-mediated thromboinflammatory organ dysfunction will be explored, with linkages to clinical biomarkers of platelet homeostasis that aid in the diagnosis and prognostication of human sepsis. Lastly, we discuss novel therapeutic opportunities that take advantage of our evolving understanding of platelets and intravascular immunity in severe infection.

Keywords: platelets, sepsis, intravascular immunity, infection, thromboinflammation

\section{INTRODUCTION}

Expanding beyond their well-known role in primary hemostasis, much of the recent research in the field of platelet biology has focused on elucidating the contributions of platelets to host defense and immunity. It is now well-established that platelets are integral to the innate immune response to infection and inflammation, both as autonomous effectors as well as collaborative conductors of anti-microbial defenses (1-6). The orchestral role of platelets in host defense is exemplified by their contribution to the intravascular immune response that unfolds during acute systemic 
infections, mediating host defense against microbial invaders while simultaneously contributing to organ dysfunction in sepsis (7). Below, we provide a comprehensive review of the cellular and molecular mechanisms of platelet functions in intravascular immunity as well as the pathogenesis of disease in sepsis. As detailed in the sections to follow, much has been learned from laboratory research and animal models of bacterial sepsis and endotoxemia, but it is helpful to begin with clinical observations from human sepsis that emphasize the critical importance of platelets in the pathogenesis of this systemic inflammatory disease.

\section{PLATELETS AND SEPSIS: THE CLINICAL PERSPECTIVE}

Abnormalities of platelet homeostasis are common during acute infections and sepsis, and clinical monitoring of platelet counts has emerged as one of the most important biomarkers in the management of septic patients (8). The most commonly monitored platelet parameter is the peripheral blood platelet concentration, which is measured routinely (often daily) in hospitalized patients with acute infections. While quantitative assessments of platelets may seem rudimentary (and lacking information about functional properties), many clinical, and epidemiological studies have identified the peripheral blood platelet count as a useful diagnostic and prognostic biomarker in sepsis (9-22).

An acute rise in the circulating platelet count (acute thrombocytosis) is generally interpreted as a manifestation of systemic inflammation, as may be seen in the context of acute infection (23). However, the most common perturbation seen in acute infection and sepsis is a reduction in circulating platelets, and the development of acute thrombocytopenia (24). In fact, observational studies of the incidence and prevalence of thrombocytopenia in critically ill patients with sepsis and septic shock have reported that low platelet counts occur in 15-50\% of patients $(13,16,25,26)$. Furthermore, among patients with normal platelet counts on admission, up to $44 \%$ will subsequently develop thrombocytopenia during the course of their stay in the intensive care unit $(16,21)$.

In addition to being a common finding in sepsis, clinicians have long appreciated that thrombocytopenia represents an ominous sign in the setting of severe infection (9-11, 14-20, 22). This clinical acumen is supported by data from multiple studies finding strong associations between low circulating platelet counts and adverse clinical outcomes in septic patients $(9,16$, 19, 21, 22, 25, 26). Likewise, failure of platelet counts to recover into the normal range during acute illness is also associated with increased mortality, whereas recovery of platelet counts is strongly associated with survival to ICU discharge (14, 17, 18). The importance of this link between thrombocytopenia and sepsis pathogenesis is now solidified by the inclusion of thrombocytopenia as a core criterion for the diagnosis of sepsis. The updated consensus definition of sepsis uses the Sepsis-related Organ Dysfunction Score (SOFA) score, in which platelet count represents 1 of 6 core parameters (27). Impressively, severe thrombocytopenia carries the same prognostic significance in the SOFA score as major organ failure requiring life-support interventions (e.g., respiratory failure requiring mechanical ventilation, circulatory shock requiring vasopressors, severe renal and hepatic failure, or coma). Clearly, circulating platelet counts are an important biomarker of disease severity and clinical outcomes in sepsis.

The strong epidemiological links between abnormalities of platelet homeostasis and outcomes strongly support a role for platelets in the pathogenesis of sepsis and septic shock. The development of thrombocytopenia in sepsis occurs primarily as a result of massive consumption of circulating platelets through interactions with immune cells in the vasculature (described below), with additional contributions from reduced thrombopoiesis, sequestration, thrombotic microangiopathy (disseminated intravascular coagulation, DIC), direct pathogen-induced thrombocytopenia, immunemediated thrombocytopenia, drug induced thrombocytopenia, and hemophagocytosis [see recent reviews by (8) and (28)]. Although thrombocytopenia is also seen in other causes of critical illness (trauma, burns, and others), it has been found that critical ill patients with burns develop more severe thrombocytopenia if there is concomitant infection and sepsis which is also linked to an increased risk of death, suggesting that sepsis-associated thrombocytopenia may have unique mechanisms of pathophysiology $(29,30)$. While much of our understanding of platelet functions in the immunopathogenesis of sepsis comes from elegant animal models of disease, a number of clinical studies have also shed light on the linkages between platelets and immunity in sepsis. Claushius et al. analyzed associations between admission platelet counts and immune phenotypes in 937 consecutive patients with sepsis admitted to 2 ICUs in the Netherlands, and found a strong association between severe thrombocytopenia, disease severity (APACHE IV score), and increased 1-year mortality (26). Using a propensity-matching strategy (to limit potential confounding by disease severity), the investigators found that, compared to patients with normal platelet counts, those with severe thrombocytopenia had higher levels of proinflammatory cytokines as well as increased markers of endothelial cell activation (increased sICAM-1 and fractalkine) and vascular permeability. Similar findings were reported in a cohort of critically-ill septic patients in Greece, in whom platelet counts varied inversely with serum pro-inflammatory cytokines and soluble ICAM-1 levels (31). Using whole blood transcriptomics, it was also shown that severe thrombocytopenia was associated with up-regulation of both pro- and anti-inflammatory signaling pathways, TLR signaling, and suppression of leukocyte adhesion molecule genes (26). Together, these findings indicate that platelet consumption and the development of thrombocytopenia is intimately associated with the dysregulated immune response that defines sepsis (27). In the following sections, the cellular and molecular mechanisms underlying these clinical observations will be reviewed in detail to explore the biological role of platelets in the intravascular immune response to infection, as well as the pathogenesis of sepsis. 


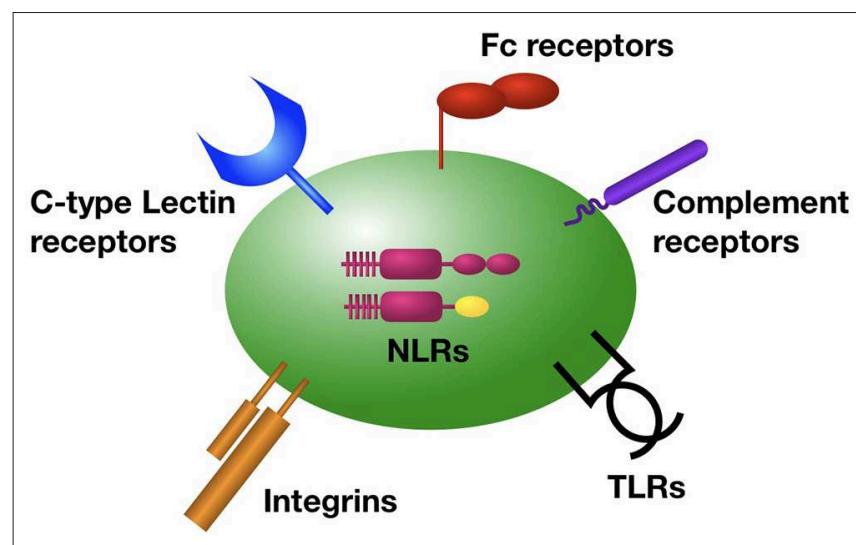

FIGURE 1 | Platelet receptors for the detection of bacterial pathogens in the bloodstream. Platelets are equipped with a diverse array of surface and intracellular receptors for pathogen detection, enabling their function as intravascular sentinel cells. These include receptors for the detection of bacterial produces and molecules (TLRs, NLRs, C-type lectins, integrins, GP1ba), as well as bacteria that have been coated by antibody (Fc recpetors), complement (complement receptors), or von Willibrand factor (integrins and GP1b $\alpha)$.

\section{PLATELETS AND INTRAVASCULAR IMMUNITY IN SEPSIS}

\section{Platelets Are Immune Sentinels for Rapid Detection of Bloodstream Invaders}

Intravascular immune sentinels are strategically positioned within the vasculature to rapidly detect and respond to bloodstream invaders (32). Platelets play critical, yet underappreciated roles in the detection of pathogens in the bloodstream, and the elicitation of a coordinated immune response. Platelets are equipped with a comprehensive set of receptors that rapidly respond to invading pathogens and pathogen-associated molecular patterns (PAMPs) (Figure 1).

\section{Toll-Like Receptors}

Like other immune sentinels, platelets express functional TollLike Receptors, including TLR 1, 2, 3, 4, 6, 7, 9 (33-40). However, activation of TLR signaling in platelets elicits a response that differs in many ways from other immune cells. First, platelets lack a nucleus, and therefore their response consists of an entirely post-transcription program. Platelet TLR signaling is incompletely understood, but appears to involve both MyD88-dependent and MyD88-independent signal transduction, including the activation of transcription factors such as NF-кB [recently review by $(33,41,42)]$. However, because platelets lack nuclei, these pathways lead to effector mechanisms that are independent of classical transcription programs, but the precise pathway details have not yet been fully elucidated [see (43) for a contemporary review]. Secondly, the activation thresholds for platelet TLRs have been found to differ from other immune cells in the context of sepsis and endotoxemia. The concentrations of LPS required to activate platelets via TLR4 in vitro is significantly higher than that required for activation of neutrophils (39). It has been hypothesized that this differential sensitivity to bacterial products allows platelets to reserve their arsenal for severe bloodstream infections with high concentrations of circulating PAMPs, thereby sparing the host from potential thromboinflammatory complications during minor infections (39). Thirdly, stimulation of platelets with LPS produces a functionally unique response compared to stimulation by other platelet activating substances $(37,39,44)$. For example, Clark et al. found that stimulation of human platelets with classical activators like thrombin or PAF induced up-regulation of P-selectin, degranulation, and aggregation in vitro, while LPS did not (39). Instead, LPS induced a unique response linked to host defense, including adhesion to activated neutrophils and fibrinogen without marked aggregation or degranulation. Others have demonstrated a variety of additional effector functions elicited by TLR4 signaling in platelets, including the release of IL-1 $\beta$ and TNF $\alpha$, tissue factor, and other immunostimulatory molecules, and augmented phagocytosis of platelets that are bound by autoantibodies (35, 36, 41, 4547). Recently, it was shown that platelet TLRs can discriminate the nuances of specific PAMP characteristics, enabling tailored responses to different pathogens. Berthet et al. found that stimulation of platelets with structurally unique isoforms of LPS derived from E. coli or Salmonella yielded distinct responses (45). It was observed that incubation of PBMCs with supernatant from platelets stimulated with S. enterica LPS elicited significantly higher levels of IL-6, IL-8, and TNF $\alpha$ compared with supernatant from E. coli LPS-stimulated platelets. The mechanisms that enable platelet TLR4 signaling to discriminate between pathogen-specific LPS isoforms remains unknown, but these observations indicate that platelet sentinels possess the sensitivity to differentiate between microbes and induce tailored responses. Taken together, the versatile functions of platelet TLRs exemplify the sentinel characteristics of platelets in the bloodstream; poised to rapidly but precisely identify invading pathogens and initiate an appropriate and tailored response.

\section{Other Pathogen Detection Mechanisms}

In addition to TLRs, platelets are equipped with a variety of other receptors to detect pathogen invasion (Figure 1). Platelets have been shown to express functional intracellular patternrecognition receptors (PRRs) including NOD2 and NLRP3, but their physiologic function in platelets remain to be defined $(48,49)$. Platelets can also recognize and respond to bacteria that have been opsonized by humoral mediators of innate and adaptive immunity (50). Fixation of $\mathrm{C} 3 \mathrm{~b}$ to the surface of bacteria can be recognized by platelets in a GP1b-dependent manner, resulting in the formation of circulating platelet-bacteria complexes that facilitate delivery of bacteria to professional phagocytes (51). Human platelets also express a range of functional immunoglobulin Fc receptors for IgG, IgA, and IgE to detect antibody-laden bacteria (50). Platelet GPIIbIIIa $(\alpha \operatorname{IIb} \beta 3)$ and GP1b $\alpha$ can also facilitate binding to bacteria, either directly to bacterial surface proteins or via molecular bridges provided by fibrinogen, fibronectin, or von Willibrand factor (52). Platelets express C-type lectin receptors CLEC-2 and DC-SIGN that have been shown to mediate binding to viral 
particles, and also contribute immunomodulatory effects during bacterial sepsis $(53,54)$. Lastly, collaboration between multiple receptor types may be required for platelets to detect and respond pathogens. For example, the response of human platelets to both Gram-positive and Gram-negative bacteria was shown to be dependent on Fc $\gamma$ RIIA activation by IgG-bound bacteria, but only with concomitant engagement of GPIIbIIIa ( $\alpha \operatorname{IIb} \beta 3$ ) $(55,56)$.

In addition to direct sensing of bacteria and bacterial products, platelets can become activated in response to inflammatory mediators liberated by other sentinels during acute infection. Platelets are decorated with a number of cytokine and chemokine receptors that detect prototypical signals of acute inflammation (57). Furthermore, platelets are potently activated by a variety of damage-associated molecular patterns (DAMPs) that are released from stressed and dying cells during acute infection. Interestingly, intravenous administration of purified danger signals such as histone proteins induces profound platelet activation and thrombocytopenia similar to that seen during endotoxemia and sepsis (58). Therefore, platelets are endowed with the machinery to detect and respond to both primary (bacteria and bacterial products) and secondary (DAMPs and inflammatory mediators) signals of acute infection, providing the necessary redundancy to function as effective sentinels within the bloodstream.

Lastly, in addition to their ability to detect passively circulating signals of pathogen invasion, platelets also conduct active surveillance of the microcirculation to enable a rapid and focused response to endovascular pathogens. Intravital imaging analysis of platelet behavior within the microcirculation of highly vascular organs (lungs, liver, brain) has revealed that platelets undergo transient touch-andgo interactions with the vascular endothelium and other intravascular immune cells such as Kupffer cells in the liver (59). Under homeostatic conditions, platelets were observed to instantaneously touch-down in a GP1b-dependent manner, and in the absence of bacteria would immediately release and return to the circulation (59). When pathogenic Grampositive bacteria such as Bacillus cereus or Staphylococcus aureus were introduced into the bloodstream and captured by liver Kupffer cells, these touch-and-go interactions converted to adhesion and aggregation nucleated around the captured bacteria. Mice deficient in GP1b $\alpha$, which were incapable of touch-and-go interactions, rapidly succumbed to overwhelming infection, demonstrating that platelet surveillance is essential for effective host defense against blood-borne bacteria (59). It remains unknown whether this active microvascular surveillance is required for control of other types of bloodstream infections (Gram negative, fungal, parasitic), and how this behavior is regulated to avoid overwhelming microvascular thrombosis. In addition, further research is required to define the molecular events that enable platelets to convert from surveillance to aggregation upon pathogen encounter, and whether dysregulation of this behavior contributes to disease pathogenesis in sepsis and other thromboinflammatory disorders.

\section{Platelets and Microvascular Traffic Control in Sepsis}

The early phase of sepsis is characterized by a vigorous systemic inflammatory response, during which platelets (together with leukocytes, primarily neutrophils) are recruited from the circulation and sequestered within highly vascular organs such as the lungs and liver, resulting in consumptive thrombocytopenia $(37,39,60-65)$. Interestingly, although the spleen is a reservoir for large numbers of platelets, studies that have tracked radio-labeled platelets in the circulation of septic mice have found little contribution of the spleen to the development of thrombocytopenia in sepsis $(37,65)$. Once considered a non-specific and maladaptive reaction to severe infection, contemporary evidence suggests that the recruitment of platelets into the microcirculation of the liver and lungs is part of a highly coordinated intravascular immune response involving collaboration between platelets and leukocytes (7). Platelets have emerged as central regulators of the intravascular immune response, beginning with the orchestration of immune cell trafficking within the inflamed microvasculature. In this section, we will discuss the role of platelets in the coordination of immune cell recruitment to inflamed tissues during infection and inflammation, followed in the next section by a review of the role of platelets in regulating antibacterial functions of immune effector cells.

Platelets engage in a reciprocal relationship with neutrophils to coordinate their recruitment and function within the microvasculature. A number of studies have reported that depletion of neutrophils or inhibition of neutrophil recruitment prevents platelet consumption and the development of thrombocytopenia, suggesting that neutrophils are essential for platelet sequestration within the microcirculation $(39,62)$. Indeed, direct visualization of platelet-neutrophil dynamics in the pulmonary and hepatic microcirculation using intravital microscopy has shown that neutrophil adhesion is followed immediately by platelet binding and aggregation upon their surface (62, 66-68). Similar mechanisms of neutrophildependent platelet recruitment have been observed in a number of organ systems, and across a variety of sepsis models $(37,39,62,64,66)$. A number of adhesion mechanisms can support platelet binding to neutrophils under flow conditions. First, selectin-mediated interactions can support adhesion between platelets and neutrophils in vitro and in vivo via both direct and indirect mechanisms. Interactions between selectins and selectin-ligands are best known for mediating transient low-affinity catch-bonds that support leukocyte rolling on activated endothelium $(69,70)$. In contrast, binding between platelet P-selectin and neutrophil PSGL-1 can mediate stable adhesion between these cells $(61,68,71,72)$. Given the lowaffinity nature of their binding, it is likely that P-selectin-PSGL1 interactions between platelets and neutrophils are particularly effective within the low-shear environment of the pulmonary and hepatic capillaries. Furthermore, PSGL1 engagement can amplify platelet-neutrophil adhesion by stimulating "outsidein" signaling pathways in neutrophils (including Src-family kinase and MAP kinase pathways) that induce the activation of integrins (73-76). Neutrophil Mac-1 $\left(\alpha_{M} \beta_{2}\right.$ integrin) can 
mediate adhesion to platelets via multiple receptors, including GP1b $\alpha$ as well as GPIIbIIIa via a fibrinogen bridge $(77,78)$. Alternatively, it has been shown that binding between human neutrophils and platelets in response to plasma from septic patients can be mediated by engagement of LFA-1 $\left(\alpha_{L} \beta_{2}\right.$ integrin) and ICAM-2 (62).

The multitude of adhesion mechanisms that support plateletneutrophil binding reflects the complexity of their interactions in vivo. Studies using intravital microscopy have revealed that adherent neutrophils nucleate the formation of large, dynamic aggregates that fluctuate in size over time as a result of continuous binding and release of circulating platelets $(62,66$, 67). Furthermore, these dynamic platelet aggregates migrate throughout the vasculature atop neutrophils as they crawl along the endothelial surface $(62,66,67)$. The molecular mechanisms that regulate this dynamic aggregation and the functional role of continuous platelet recycling atop neutrophils are unclear, but are likely tightly controlled to avoid catastrophic microvascular thrombosis.

Under certain inflammatory contexts (primarily noninfectious), the recruitment of platelets and neutrophils within the microcirculation may follow the opposite sequence, that is, initial platelet accumulation upon the endothelium followed by subsequent neutrophil recruitment. This mode of plateletdependent neutrophil recruitment has been observed in a number of models of inflammatory and thrombotic disease, including cytokine-induce cerebral inflammation (79), thermal liver injury (80), acute lung injury $(61,81)$, and venous thrombosis (82). In these contexts, platelets adhere and aggregate at sites of compromised vascular integrity, and then promote neutrophil recruitment either directly through P-selectin-PSGL1 and/or integrin-mediated interactions, or indirectly through TXA1-mediated activation of endothelium (83). In instances where vascular integrity is severely disrupted, platelets can even be seen "paving" neo-vessel-like conduits through which neutrophils migrate to reach sites of inflammation (80). Thus, the trafficking and recruitment of platelets and neutrophils exists as a reciprocal relationship, in which neutrophils may recruit platelets, and platelets may recruit neutrophils. The mechanisms that dictate neutrophil-first vs. platelet-first recruitment are not well-understood. It is possible that the nature of the inflammatory stimulus (e.g., infectious vs. non-infectious), or the microvascular characteristics (endothelial integrity, adhesion molecule expression) may induce different patterns of cell recruitment to tailor the intravascular immune response to the inciting stimulus. As described in the sections below, this hypothesis is supported by evidence that neutrophil effector functions can differ in response to platelet-first compared to neutrophil-first recruitment interactions (80).

Following adhesion to the endothelium, immune cells migrate through the vasculature guided by a variety of chemotactic cues (84-86). The platelet payload includes a number of chemoattractant factors that can guide the chemotaxis of neutrophils and other leukocytes (4). In addition, platelets may directly influence neutrophil chemotaxis within blood vessels through contact-mediated interactions on specific microdomains of the neutrophil surface. Sreeramkumar et al. conducted a detailed in vivo investigation of neutrophil polarization (an essential pre-requisite for directional migration), and made the striking discovery that platelets dock to the leading-edge of adherent neutrophils in the vasculature, and that this polarized binding was crucial for directional migration (68). Following engagement of platelet P-selectin to PSGL-1 on the leading edge of neutrophils, outside-in signal transduction led to a redistribution of surface receptors Mac- $1\left(\alpha_{M} \beta_{2}\right.$ integrin) and CXCL2, generating polarized receptor microdomains that were essential for effective locomotion toward infection and injury. This discovery revealed that adherent neutrophils scan for activated platelets in the vasculature to enable physical interactions that steer neutrophil migration toward appropriate targets.

Lastly, like other innate immune cells, platelets themselves possess a rudimentary ability to migrate (undergo chemotaxis) in response to chemoattractant stimuli. Platelets express a variety of surface receptors for prototypical chemoattractants, as well as the necessary intracellular signal transduction and cytoskeletal machinery required for cell motility. Platelet chemotaxis remained an in vitro observation for many years (4), until a number of recent studies demonstrated evidence of platelet migration in vivo in mouse models of allergic pneumonitis and sepsis $(87,88)$. Directional migration of platelets in vivo relies on integrin-based interactions, as blockade of GPIIbIIIa ( $\alpha \mathrm{IIb} \beta 3$ ) integrin inhibits intravascular platelet locomotion (88). The physiologic function of platelet locomotion remained a biological curiosity until recently, when Massberg et al. published a seminal study detailing a functional contribution of platelet migration to anti-bacterial host-defense in vivo (88). The authors observed that migrating platelets behaved as "mechano-scavengers" within the vasculature, pilingup substratum and other particles (including bacteria) as they moved. This mechano-scavenger behavior enabled platelets to collect bacteria that they encountered in their travels, bundling them within open cannalicular systems (OCS) for disposal by professional phagocytes. Therefore, migration of platelets appears to fill an important niche in the intravascular immune response by contributing to the collection and clearance of pathogens in collaboration with local phagocytes.

\section{Platelets and Neutrophils: Partners in Intravascular Immunity During Sepsis}

Platelets have emerged as versatile effectors of antibacterial immunity, contributing both autonomous bacteriocidal/bacteriostatic properties as well as synergistic partnerships with other innate immune cells. In co-culture experiments, platelets can autonomously inhibit the growth of various bacteria (89-91). The anti-bacterial properties of platelets have largely been attributed to their ability to produce anti-microbial peptides such as $\beta$-defensins and so-called "platelet-microbicidal proteins" (PmP) [reviewed by (50)]. In addition, it has been observed that platelets exhibit a rudimentary ability to engulf bacteria (92). However, the functional significance of these autonomous anti-bacterial properties in the context of in vivo host defense remains unknown. 
In contrast, platelets have well-defined anti-bacterial functions in vivo that arise from synergistic partnerships with other immune cells (Figure 2). For example, platelets are crucial for survival in mouse models of Bacillus cereus and Staphylococcus aureus bacteremia due to their ability to collaborate with liver macrophages to clear circulating bacteria (59). During these infections, platelets were observed to aggregate upon bacterialaden macrophages in the liver, providing an essential signal to macrophages that enabled clearance of bacteria from the circulation and protection against overwhelming sepsis (59). In addition, circulating platelets can scavenge blood-borne bacteria and enhance their delivery to phagocytes (51). However, it should be noted that under certain circumstances, plateletmediated bacterial "opsonization" may actually impair clearance of bacteremia by diverting microbes toward less-efficient phagocytes, as is seen in Listeria monocytogenes infection (51).

The most extensively studied and perhaps most potent platelet-mediated anti-bacterial responses are generated through collaboration between platelets and neutrophils. Platelet-neutrophil interactions induce and/or augment a number of anti-bacterial neutrophil functions to enhance the clearance of bacteria from the bloodstream. First, neutrophil phagocytosis of extracellular bacteria is augmented by mediators released from activated platelets $(93,94)$. In addition, platelets augment intracellular killing of bacteria within neutrophils by promoting oxidative burst generation through both contactdependent outside-in signaling as well the release of various soluble mediators $(76,95,96)$. In addition to augmenting phagocytosis and intracellular killing, platelets help supply neutrophils with their prey through mechano-scavenging behavior in the microvasculature, bundling stray bacteria for efficient phagocytosis and clearance by neutrophils (and other phagocytes) (88).

Lastly, the most potent anti-microbial effector mechanism unleashed in response to platelet-neutrophil interactions is the neutrophil extracellular trap (NET). NETs are extracellular webs of decondensed chromatin laden with proteolytic enzymes and other anti-bacterial molecules that are expelled from activated neutrophils (97). NETs are capable of both capturing and directly killing extracellular microbes, including bacteria, fungi, parasites, and even display anti-viral properties (98). Although a number of activating stimuli can induce NETs release from neutrophils, activated platelets have emerged as one of the most potent stimuli for NETs release, and platelet-induced NETs have been observed in a variety of sepsis models as well as other noninfectious inflammatory conditions $(39,62,63,82,99-101)$. During sepsis, neutrophils cast NETs into the bloodstream to filter pathogens from the circulation $(39,62,63)$. This powerful and efficient bacterial clearance system is strategically positioned within the microcirculation of highly vascular organs (liver and lung), enabling maximal filtration of the cardiac output to protect against hematogenous dissemination of infection (62).

The molecular mechanisms controlling NETs release in response to platelet-neutrophil interactions are incompletely understood. Blocking the physical engagement of platelets with neutrophils inhibits the release of NETs, suggesting a contactdependent induction pathway. However, while contact between neutrophils and platelets is essential for intravascular NETs release in vivo, it is not sufficient. Using a mouse model of sterile pulmonary inflammation, Rossaint et al. found that a second signal composed of platelet-derived CXCL4/CCL5 heterodimers was essential for NETs release in response to platelet-neutrophil binding (100). In vitro, $\beta$-defensin-1 released from activated human platelets was shown to induce NETs release from neutrophils, but this is yet to be confirmed in vivo (89). A full understanding of the molecular mechanisms of plateletmediated NETs release during bacterial sepsis in vivo remains to be elucidated.

Finally, although platelet-neutrophil collaboration has been studied more extensively, it should be noted that platelets engage in functional interactions with other innate immune cells in the vasculature during sepsis. Platelet-monocyte complex formation has been observed in the blood of septic patients (102, 103), and the levels of circulating platelet-monocyte complexes may be a useful biomarker to predict adverse outcomes in older adults with sepsis (102). Functionally, platelets have been shown to aid in the recruitment of monocytes to foci of Listeria monocytogenes infection in mice, as well as modulate the inflammatory phenotype of monocytes during viral infection $(104,105)$. Platelets have also been shown to modulate the polarization, cytokine profile, and antibacterial effector mechanisms of macrophages in animal models of sepsis $(59,91,106,107)$.

Overall, there is strong evidence that collaboration between platelets, neutrophils, and other antibacterial effector cells within the microvasculature is crucial to protect against bloodborne infections. Unfortunately, as with most powerful immune defense mechanisms, dysregulation of the intravascular immune response during sepsis can result in tremendous collateral damage to host cells and tissue, resulting in organ dysfunction.

\section{Platelets-Neutrophil-NETs Axis and Organ Dysfunction in Sepsis}

The intricate interplay between platelets, neutrophils, and NETs in sepsis represents a classical example of a "double-edged sword"; providing protective host defense while simultaneously causing immune-mediated organ dysfunction (Figure 3). The importance of this axis in sepsis pathogenesis has been confirmed in a variety of animal models of acute infection, in which therapeutic blockade of the platelet-neutrophil-NETs axis reduced organ dysfunction and (in some models) improved survival $(62,67,108-115)$. Platelets and neutrophils conspire together to induce microvascular dysfunction and tissue damage through a variety of mechanisms. In particular, the release of NETs in response to platelet-neutrophil engagement can be especially cytotoxic to host cells. During sepsis, NETs can be found throughout the vast microvasculature of the liver and other organs, exposing the endothelium and underlying parenchyma to a variety of potent cytotoxic mediators. First, extracellular histones proteins contained within the chromatin backbone of NETs are particularly cytotoxic to endothelial cells and parenchymal cells in vitro and in vivo (116). In fact, Esmon et al. revealed that antibody-mediated neutralization 


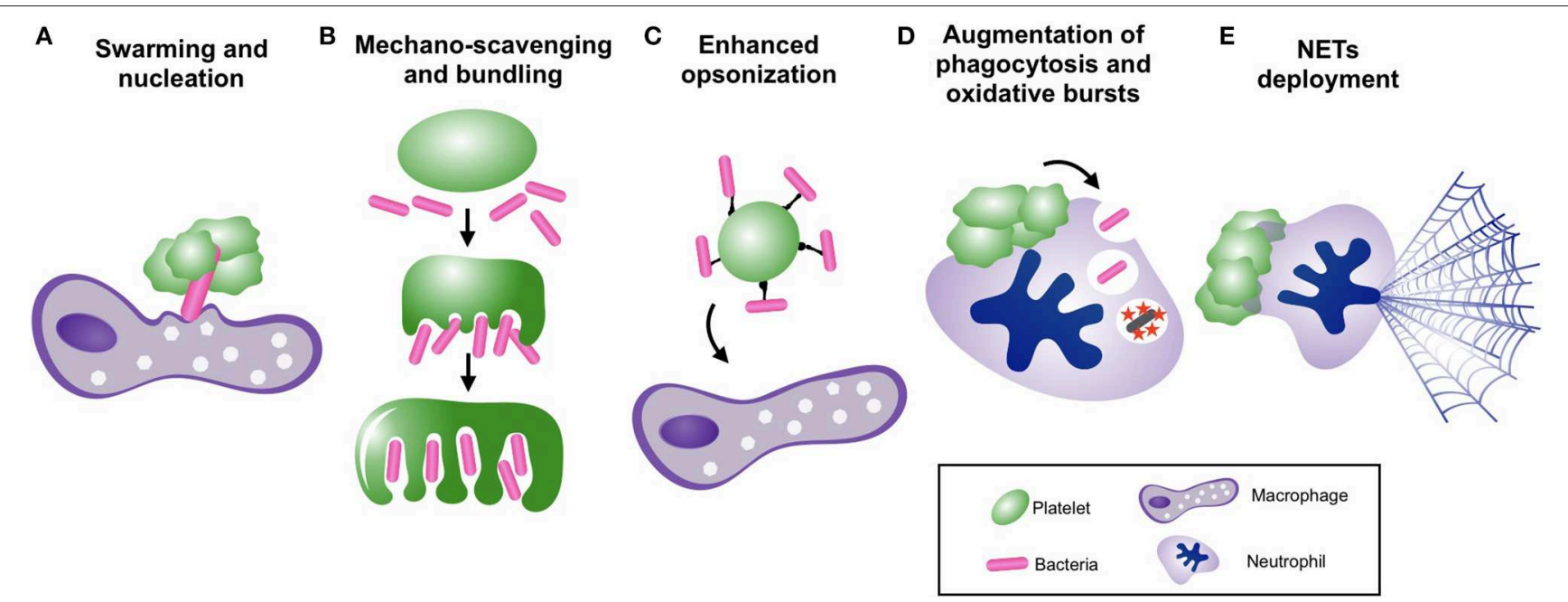

FIGURE 2 | Platelets collaborate with neutrophils and other immune cells to facilitate bacterial clearance from the bloodstream. Mechanisms of bacterial clearance facilitated by platelet-leukocyte interactions, including, (A) vascular surveillance and nucleation of bacterial invaders to promote phagocytosis by macrophages, (B) mechano-scavenging of bacteria within the microvasculature, (C) "opsonization" of circulating bacteria for clearance by phagocytes (D) augmentation of neutrophil-mediated phagocytosis and oxidative killing, and (E) induction of neutrophil extracellular trap (NET) release.

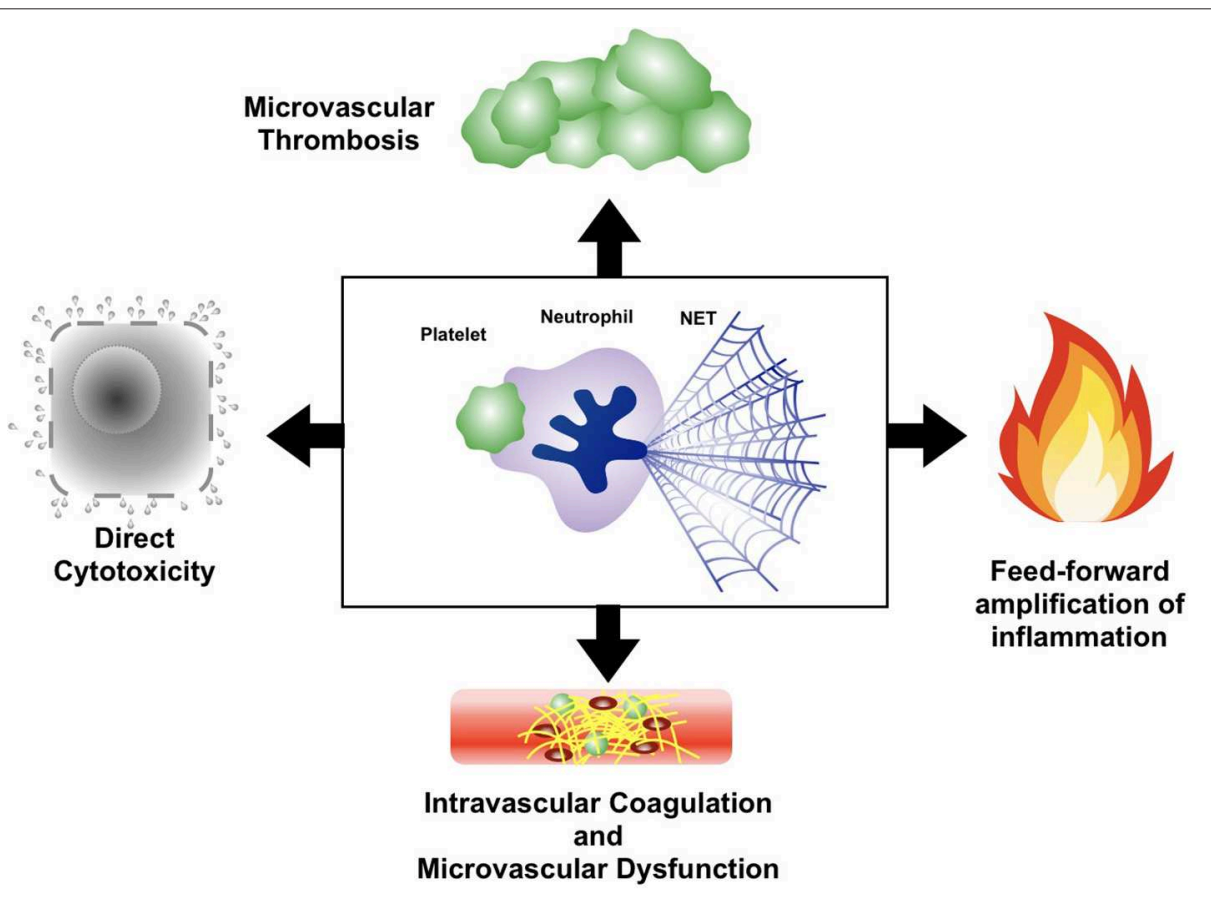

FIGURE 3 | Mechanisms of organ dysfunction in sepsis induced by the platelet-neutrophil-NETs axis. Intravascular collaboration between platelets, neutrophils, and NETs leads to cell and tissue damage as a result of directly cytotoxicity, induction of intravascular coagulation and microvascular dysfunction, and propagation of a dysfunctional thromboinflammatory response through feed-forward microvascular inflammation and thrombosis.

of histone proteins in a mouse model of polymicrobial sepsis protected against multi-organ dysfunction and death (116). Furthermore, NETs contain an abundance of proteolytic and antimicrobial proteins that can damage host cells and tissues. For example, genetic deficiency of neutrophil serine proteases such as neutrophil elastase, or blockade of their enzymatic activity with small molecule inhibitors, resulted in a dramatic decrease in biomarkers of tissue damage in mouse models of acute infection (115). Lastly, the fact that many NETs components can serve as pro-inflammatory DAMPs (DNA, histone proteins, proteolytic enzymes, antimicrobial peptides, and others) creates in a feed-forward system that propagates microvascular inflammation and amplifies tissue damage. 
TABLE 1 | The role of platelets in host defense during bacterial infection in the bloodstream.

\begin{tabular}{|c|c|c|}
\hline Host response in sepsis & Roles of platelets & Selected references \\
\hline \multirow[t]{2}{*}{ Pathogen detection } & Direct detection of invading pathogens (see Figure 1) & $(34,35,37,39)$ \\
\hline & Intravascular surveillance behavior & $(59,88)$ \\
\hline \multirow[t]{3}{*}{ Pathogen capture and killing } & Direct platelet-mediated cytotoxicity & $(89-91)$ \\
\hline & Enhanced opsonization & $(36,51,53,59)$ \\
\hline & Enhancement of leukocyte-mediated capture and killing & $(51,59,62,88,93,94)$ \\
\hline \multirow{3}{*}{ Modulation of immune cell trafficking and function } & Neutrophil trafficking and function & $(61,68,79,81)$ \\
\hline & Monocyte trafficking and function & $(102-105)$ \\
\hline & Macrophage polarization and function & $(59,91,106,107)$ \\
\hline \multirow[t]{2}{*}{ Modulation of systemic inflammatory response } & Inflammatory mediator release from platelets & $(36,46,47)$ \\
\hline & Inflammatory-mediator production by innate immune cells & $(26,45,106)$ \\
\hline
\end{tabular}

In addition to direct cytotoxicity, a growing body of literature implicates the platelet-neutrophil-NETs axis in sepsis pathogenesis through the induction of intravascular coagulation. Platelet-neutrophil interactions and the subsequent release of NETs coincides with diffuse activation of thrombin and fibrin deposition within the vasculature of multiple organs (67). Imaging of this process in vivo has revealed disseminated microvascular coagulation following NETs release, resulting in extensive obstruction of blood flow and ischemic injury to the affected organ (67). This widespread microvascular coagulation was largely NETs dependent, as mutant mice with severely reduced NETs production (peptidylarginine deiminase 4 [PAD4] deficient mice) have markedly diminished intravascular coagulation and organ injury, yet still have abundant neutrophilplatelet aggregation in the microvasculature (67). Conversely, studies using DNase-deficient mice have revealed that impaired clearance of NETs (leading to an overabundance of NETs in the vasculature) precipitates extensive microvascular coagulation and thrombosis. In fact, administration of endotoxin to DNase1deficient or DNase-like-3 deficient mice resulted in multi-organ microvascular coagulation and microangiopathic hemolytic anemia characteristic of disseminated intravascular coagulation (DIC), followed by death within hours (112). There is also emerging evidence from human studies that NETs promote hypercoagulability in patients with sepsis, and that elevated levels of circulating NETs is associated with sepsis-related disseminated intravascular coagulation (117-119).

The pro-coagulant properties of NETs arise from a variety of components that are known to interact with the clotting cascade at multiple levels. For example, histone proteins have been shown to initiate coagulation through the upregulation of tissue factor as well as initiation of the contact-dependent pathway (63, $82,120)$. Indeed, antibody-mediated neutralization of histone H4 within NETs in a mouse model of Gram-negative sepsis reduced intravascular thrombin generation in the liver and lung microcirculation (67). Furthermore, neutrophil serine proteases present within NETs (such as neutrophil elastase and cathepsin $\mathrm{G}$ ) activate tissue factor- and factor XII-dependent coagulation pathways, and also promote platelet activation through proteaseactivated receptors (PARs) $(63,121)$. NETs may also acquire procoagulant factors from the bloodstream to bolster their ability to initiate and propagate microvascular coagulation. Circulating microparticles are captured by NETs that can augment thrombin generation via factor XII and the intrinsic pathway (122). Lastly, cross-talk between intravascular NETs and endothelial cells leads to upregulation of tissue factor expression and direct activation of the coagulation cascade within the vessel lumen (123).

Although a number of components within NETs have the ability to activate coagulation in isolation, emerging evidence suggests that the induction of intravascular coagulation in vivo requires the intact NETs macrostructure. Most notably, experiments using exogenous DNase to dissolve the DNA backbone of NETs have demonstrated marked inhibition of intravascular thrombin activation and fibrin production, despite the fact that individual pro-coagulant NETs components remain in the vasculature $(67,122)$. These findings suggest that intact NETs provide an essential catalytic scaffold for the induction of disseminated intravascular coagulation during sepsis.

Finally, in addition to stimulating NETs release from neutrophils, platelets also provide synergistic amplification of NET-induced coagulation. While the majority of platelets are sequestered in the microvasculature through interactions with neutrophils, platelets can also bind and aggregate directly on NETs. NETs-mediated platelet aggregation has been demonstrated in a variety of thromboinflammatory disorders, including sepsis, venous thromboembolic disease, and atherosclerotic vascular disease $(67,124,125)$. During sepsis, platelets aggregate within intravascular NETs and amplify thrombin generation. The molecular crosstalk between platelets and NETs that propagates intravascular coagulation is incompletely understood, but one study identified platelet polyphosphate (released from dense granules) as an essential 
signal for NETs-mediated thrombin activation in vivo (67), and polyphosphate has been identified as a cofactor for histone H4-mediated thrombin activation in vitro (120). Overall, the extensive cross talk between platelets, neutrophils, and NETs results in widespread intravascular coagulation, microvascular occlusion, and ischemic and cytotoxic organ damage that is characteristic of sepsis pathology.

\section{CONCLUSIONS}

Platelets are versatile mediators of antimicrobial immunity and host defense within the bloodstream during sepsis (Table $\mathbf{1}$ ). However, dysregulation of this platelet-mediated intravascular immune response leads to tissue damage, intravascular coagulation, and organ dysfunction. The pathological integration of immunity, thrombosis, and coagulation in sepsis provides a glimpse into why clinical trials of anti-inflammatory or anticoagulant therapies alone have yielded underwhelming results, and underscores the importance of creating novel therapies that target keystone mechanisms in this complex pathological system. The integrated response of platelets, neutrophils, and NETs represents one such keystone mechanism, with a growing body of literature demonstrating therapeutic efficacy of targeting this system in animal models of sepsis and other acute inflammatory diseases. In humans, retrospective studies of patients with septic shock have found that anti-platelet agents may reduce the risk of end-organ dysfunction and even mortality (128-130). Furthermore, the upcoming AspiriN To Inhibit SEPSIS (ANTISEPSIS) trial will investigate the use of low-dose aspirin as a primary preventative measure to reduce sepsis-related mortality and organ dysfunction in elderly patients (131). Beyond prototypical anti-platelet

\section{REFERENCES}

1. Semple JW, Italiano JE, Freedman J. Platelets and the immune continuum. Nat Rev Immunol. (2011) 11:264-74. doi: 10.1038/nri2956

2. Koupenova M, Clancy L, Corkrey HA, Freedman JE. Circulating platelets as mediators of immunity, inflammation, and thrombosis. Circ Res. (2018) 122:337-51. doi: 10.1161/CIRCRESAHA.117.310795

3. Rayes J, Watson SP, Nieswandt B. Functional significance of the platelet immune receptors GPVI and CLEC-2. J Clin Invest. (2019) 129:12-23. doi: 10.1172/JCI122955

4. Li JL, Zarbock A, Hidalgo A. Platelets as autonomous drones for hemostatic and immune surveillance. J Exp Med. (2017) 214:2193-204. doi: $10.1084 /$ jem. 20170879

5. Kim S-J, Davis RP, Jenne CN. Platelets as modulators of inflammation. Semin Thromb Hemost. (2018) 44:91-101. doi: 10.1055/s-0037-1607432

6. Deppermann C, Kubes P. Platelets and infection. Semin Immunol. (2016) 28:536-45. doi: 10.1016/j.smim.2016.10.005

7. Hickey MJ, Kubes P. Intravascular immunity: the host-pathogen encounter in blood vessels. Nat Rev Immunol. (2009) 9:364-75. doi: 10.1038/nri2532

8. Dewitte A, Lepreux S, Villeneuve J, Rigothier C, Combe C, Ouattara A, Ripoche J. Blood platelets and sepsis pathophysiology: a new therapeutic prospect in critically [corrected] ill patients? Ann Intensive Care. (2017) 7:115. doi: 10.1186/s13613-017-0337-7

9. Smith-Erichsen N. Serial determinations of platelets, leucocytes and coagulation parameters in surgical septicemia. Scand J Clin Lab Invest Suppl. (1985) 178:7-14. agents, other novel therapeutic targets have emerged from our understanding of the cellular and molecular mechanisms of platelet function in sepsis. For example, an abundance of preclinical data described above supports the use of therapies targeting the platelet-neutrophil-NETs axis to protect against microvascular dysfunction, organ damage, and death in models of bacterial sepsis and endotoxemia. With a growing list of direct and indirect inhibitors of NETs production and/or function, clinical trials of NETs-blockade in sepsis are on the horizon. Of course, as with any immunomodulatory therapy, blockade of the platelet-neutrophil-NETs axis may produce unwanted side effects including defects in host defense. Therefore, continued research is needed to generate optimized treatment strategies that functionally uncouple the harmful pathogenic mechanisms from the protective immune properties of this intravascular immune response.

\section{AUTHOR CONTRIBUTIONS}

$\mathrm{BM}$ performed the literature review, wrote and edited the manuscript. MD contributed to the literature review, manuscript preparation, and figure development.

\section{FUNDING}

BM was supported by a clinician fellowship from Alberta Innovates-Health Solutions, a postdoctoral fellowship from the Canadian Institutes of Health Research (CIHR), and grants from Alberta Health Services, AHS Critical Care Strategic Clinical Network, and the Cumming School of Medicine. MD was supported by a Canadian Institute of Health Research studentship.

10. Akca S, Haji-Michael P, de Mendonça A, Suter P, Levi M, Vincent J-L. Time course of platelet counts in critically ill patients. Crit Care Med. (2002) 30:753-6. doi: 10.1097/00003246-20020400 0-00005

11. Crowther MA, Cook DJ, Meade MO, Griffith LE, Guyatt GH, Arnold DM, et al. Thrombocytopenia in medical-surgical critically ill patients: prevalence, incidence, and risk factors. J Crit Care. (2005) 20:348-53. doi: 10.1016/j.jcrc.2005.09.008

12. Mavrommatis AC, Theodoridis T, Orfanidou A, Roussos C, ChristopoulouKokkinou V, Zakynthinos S. Coagulation system and platelets are fully activated in uncomplicated sepsis. Crit Care Med. (2000) 28:451-7. doi: 10.1097/00003246-200002000-00027

13. Vanderschueren S, De Weerdt A, Malbrain M, Vankersschaever D, Frans E, Wilmer A, et al. Thrombocytopenia and prognosis in intensive care. Crit Care Med. (2000) 28:1871-6. doi: 10.1097/00003246-200006000-00031

14. Strauss R, Wehler M, Mehler K, Kreutzer D, Koebnick C, Hahn EG. Thrombocytopenia in patients in the medical intensive care unit: bleeding prevalence, transfusion requirements, and outcome. Crit Care Med. (2002) 30:1765-71. doi: 10.1097/00003246-200208000-00015

15. Moreau D, Timsit J-F, Vesin A, Garrouste-Orgeas M, de Lassence A, Zahar J-R, et al. Platelet count decline: an early prognostic marker in critically ill patients with prolonged ICU stays. Chest. (2007) 131:1735-41. doi: 10.1378/chest.06-2233

16. Hui P, Cook DJ, Lim W, Fraser GA, Arnold DM. The frequency and clinical significance of thrombocytopenia complicating critical illness: a systematic review. Chest. (2011) 139:271-8. doi: 10.1378/chest.10-2243 
17. Venkata C, Kashyap R, Farmer JC, Afessa B. Thrombocytopenia in adult patients with sepsis: incidence, risk factors, and its association with clinical outcome. J Intensive Care. (2013) 1:9. doi: 10.1186/2052-0492-1-9

18. Nijsten MW, Duis ten HJ, Zijlstra JG, Porte RJ, Zwaveling JH, Paling JC, The TH. Blunted rise in platelet count in critically ill patients is associated with worse outcome. Crit Care Med. (2000) 28:3843-6. doi: 10.1097/00003246-200012000-00017

19. Sharma B, Sharma M, Majumder M, Steier W, Sangal A, Kalawar M. Thrombocytopenia in septic shock patients-a prospective observational study of incidence, risk factors and correlation with clinical outcome. Anaesth Intensive Care. (2007) 35:874-80. doi: 10.1177/0310057X0703 500604

20. Thiolliere F, Serre-Sapin AF, Reignier J, Benedit M, Constantin JM, Lebert C, et al. Epidemiology and outcome of thrombocytopenic patients in the intensive care unit: results of a prospective multicenter study. Intensive care medicine. (2013) 39:1460-8. doi: 10.1007/s00134-01 3-2963-3

21. Williamson DR, Lesur O, Tétrault J-P, Nault V, Pilon D. Thrombocytopenia in the critically ill: prevalence, incidence, risk factors, and clinical outcomes. Can J Anaesth. (2013) 60:641-51. doi: 10.1007/s12630-013-9933-7

22. Thiery-Antier N, Binquet C, Vinault S, Meziani F, BoisraméHelms J, Quenot J-P. EPIdemiology of septic shock group. is thrombocytopenia an early prognostic marker in septic shock? Crit Care Med. (2016) 44:764-72. doi: 10.1097/CCM.00000000000 01520

23. Rose SR, Petersen NJ, Gardner TJ, Hamill RJ, Trautner BW. Etiology of thrombocytosis in a general medicine population: analysis of 801 cases with emphasis on infectious causes. J Clin Med Res. (2012) 4:415-23. doi: $10.4021 /$ jocmr $1125 \mathrm{w}$

24. Levi M. Platelets in critical illness. Semin Thromb Hemost. (2016) 42:252-7. doi: $10.1055 / \mathrm{s}-0035-1570080$

25. Zarychanski R, Houston DS. Assessing thrombocytopenia in the intensive care unit: the past, present, and future. Hematology Am Soc Hematol Educ Program. (2017) 2017:660-6. doi: 10.1182/asheducation-201 7.1.660

26. Claushuis TAM, van Vught LA, Scicluna BP, Wiewel MA, Klein Klouwenberg PMC, Hoogendijk AJ, et al. Thrombocytopenia is associated with a dysregulated host response in critically ill sepsis patients. Blood. (2016) 127:3062-72. doi: 10.1182/blood-2015-11-680744

27. Singer M, Deutschman CS, Seymour CW, Shankar-Hari M, Annane $\mathrm{D}$, Bauer $\mathrm{M}$, et al. The third international consensus definitions for sepsis and septic shock (Sepsis-3). JAMA. (2016) 315:801-10. 801-810. doi: 10.1001/jama.2016.0287

28. Larkin CM, Santos-Martinez M-J, Ryan T, Radomski MW. Sepsisassociated thrombocytopenia. Thromb Res. (2016) 141:11-6. doi: 10.1016/j.thromres.2016.02.022

29. Cato LD, Wearn CM, Bishop JRB, Stone MJ, Harrison P, Moiemen N. Platelet count: a predictor of sepsis and mortality in severe burns. Burns. (2018) 44:288-97. doi: 10.1016/j.burns.2017.08.015

30. Marck RE, Montagne HL, Tuinebreijer WE, Breederveld RS. Time course of thrombocytes in burn patients and its predictive value for outcome. Burns. (2013) 39:714-22. doi: 10.1016/j.burns.2013.01.015

31. Tsirigotis P, Chondropoulos S, Frantzeskaki F, Stamouli M, Gkirkas K, Bartzeliotou A, et al. Thrombocytopenia in critically ill patients with severe sepsis/septic shock: prognostic value and association with a distinct serum cytokine profile. J Crit Care. (2016) 32:9-15. doi: 10.1016/j.jcrc.2015. 11.010

32. Elzey BD, Tian J, Jensen RJ, Swanson AK, Lees JR, Lentz SR, et al. Plateletmediated modulation of adaptive immunity. A communication link between innate and adaptive immune compartments. Immunity. (2003) 19:9-19. doi: 10.1016/s1074-7613(03)00177-8

33. Hamzeh-Cognasse H, Berthelot P, Tardy B, Pozzetto B, Bourlet T, Laradi $\mathrm{S}$, et al. Platelet toll-like receptors are crucial sensors of infectious danger moieties. Platelets. (2018) 29:533-40. doi: 10.1080/09537104.2018.1 445842

34. Shiraki R, Inoue N, Kawasaki S, Takei A, Kadotani M, Ohnishi Y, et al. Expression of Toll-like receptors on human platelets. Thromb Res. (2004) 113:379-85. doi: 10.1016/j.thromres.2004.03.023
35. Aslam R, Speck ER, Kim M, Crow AR, Bang KWA, Nestel FP, et al. Platelet Toll-like receptor expression modulates lipopolysaccharideinduced thrombocytopenia and tumor necrosis factor-alpha production in vivo. Blood. (2006) 107:637-41. doi: 10.1182/blood-2005-0 6-2202

36. Semple JW, Aslam R, Kim M, Speck ER, Freedman J. Platelet-bound lipopolysaccharide enhances $\mathrm{Fc}$ receptormediated phagocytosis of IgG-opsonized platelets. Blood. (2007) 109:4803-5. doi: 10.1182/blood-2006-12-062695

37. Andonegui G, Kerfoot SM, McNagny K, Ebbert KVJ, Patel KD, Kubes P. Platelets express functional Toll-like receptor-4. Blood. (2005) 106:2417-23. doi: 10.1182/blood-2005-03-0916

38. Cognasse F, Hamzeh H, Chavarin P, Acquart S, Genin C, Garraud O. Evidence of Toll-like receptor molecules on human platelets. Immunol Cell Biol. (2005) 83:196-8. doi: 10.1111/j.1440-1711.2005. 01314.x

39. Clark SR, Ma AC, Tavener SA, McDonald B, Goodarzi Z, Kelly MM, et al. Platelet TLR4 activates neutrophil extracellular traps to ensnare bacteria in septic blood. Nat Med. (2007) 13:463-9. doi: 10.1038/ nm1565

40. Ståhl A-L, Svensson M, Morgelin M, Svanborg C, Tarr PI, Mooney JC, et al. Lipopolysaccharide from enterohemorrhagic Escherichia coli binds to platelets through TLR4 and CD62 and is detected on circulating platelets in patients with hemolytic uremic syndrome. Blood. (2006) 108:167-76. doi: 10.1182/blood-2005-08-3219

41. Schattner M. Platelet TLR4 at the crossroads of thrombosis and the innate immune response. J Leukoc Biol. (2018) 105:873-80. doi: 10.1002/JLB.MR06 $18-213 \mathrm{R}$

42. Vallance TM, Zeuner M-T, Williams HF, Widera D, Vaiyapuri $S$. Toll-Like receptor 4 signalling and its impact on platelet function, thrombosis, and haemostasis. Mediators Inflamm. (2017) 2017:9605894-13. doi: $10.1155 / 2017 / 9605894$

43. Mussbacher M, Salzmann M, Brostjan C, Hoesel B, Schoergenhofer C, Datler H, et al. Cell type-specific roles of NF- $\mathrm{BB}$ linking inflammation and thrombosis. Front Immunol. (2019) 10:85. doi: 10.3389/fimmu.2019. 00085

44. Claushuis TAM, Van Der Veen AIP, Horn J, Schultz MJ, Houtkooper RH, van $\mathrm{t}$ Veer $\mathrm{C}$, et al. Platelet Toll-like receptor expression and activation induced by lipopolysaccharide and sepsis. Platelets. (2019) 30:296-304. doi: 10.1080/09537104.2018.1445841

45. Berthet J, Damien P, Hamzeh-Cognasse H, Arthaud C-A, Eyraud M-A, Zéni F, et al. Human platelets can discriminate between various bacterial LPS isoforms via TLR4 signaling and differential cytokine secretion. Clin Immunol. (2012) 145:189-200. doi: 10.1016/j.clim.2012.09.004

46. Brown GT, Narayanan P, Li W, Silverstein RL, McIntyre TM. Lipopolysaccharide stimulates platelets through an IL-1 $\beta$ autocrine loop. J Immunol. (2013) 191:5196-203. doi: 10.4049/jimmunol.1 300354

47. Rondina MT, Schwertz H, Harris ES, Kraemer BF, Campbell RA, Mackman N, et al. The septic milieu triggers expression of spliced tissue factor mRNA in human platelets. J Thromb Haemost. (2011) 9:748-58. doi: 10.1111/j.1538-7836.2011.04208.x

48. Zhang S, Zhang S, Hu L, Zhai L, Xue R, Ye J, et al. Nucleotidebinding oligomerization domain 2 receptor is expressed in platelets and enhances platelet activation and thrombosis. Circulation. (2015) 131:1160-70. doi: 10.1161/CIRCULATIONAHA.114.0 13743

49. Vogel S, Arora T, Wang X, Mendelsohn L, Nichols J, Allen $D$, et al. The platelet NLRP3 inflammasome is upregulated in sickle cell disease via HMGB1/TLR4 and Bruton tyrosine kinase. Blood Adv. (2018) 2:2672-80. doi: 10.1182/bloodadvances.20180 21709

50. Yeaman MR. Platelets: at the nexus of antimicrobial defence. Nat Rev Microbiol. (2014) 12:426-37. doi: 10.1038/nrmicro3269

51. Verschoor A, Neuenhahn M, Navarini AA, Graef P, Plaumann A, Seidlmeier $A$, et al. A platelet-mediated system for shuttling blood-borne bacteria to CD8 $\alpha+$ dendritic cells depends on glycoprotein GPIb and complement C3. Nat Immunol. (2011) 12:1194-201. doi: 10.1038/ni.2140 
52. Hamzeh-Cognasse H, Damien P, Chabert A, Pozzetto B, Cognasse F, Garraud O. Platelets and infections - complex interactions with bacteria. Front Immunol. (2015) 6:82. doi: 10.3389/fimmu.2015.00082

53. Chaipan C, Soilleux EJ, Simpson P, Hofmann H, Gramberg T, Marzi A, et al. DC-SIGN and CLEC-2 mediate human immunodeficiency virus type 1 capture by platelets. J Virol. (2006) 80:8951-60. doi: 10.1128/JVI.00136-06

54. Rayes J, Lax S, Wichaiyo S, Watson SK, Di Y, Lombard S, et al. The podoplanin-CLEC-2 axis inhibits inflammation in sepsis. Nat Commun. (2017) 8:2239. doi: 10.1038/s41467-017-02402-6

55. Arman M, Krauel K, Tilley DO, Weber C, Cox D, Greinacher A, et al. Amplification of bacteria-induced platelet activation is triggered by Fc $\gamma$ RIIA, integrin $\alpha I I b \beta 3$, and platelet factor 4. Blood. (2014) 123:3166-74. doi: 10.1182/blood-2013-11-540526

56. Watson CN, Kerrigan SW, Cox D, Henderson IR, Watson SP, Arman M. Human platelet activation by Escherichia coli: roles for Fc $\gamma$ RIIA and integrin aIIbB3. Platelets. (2016) 27:535-40. doi: 10.3109/09537104.2016.1148129

57. Clemetson KJ, Clemetson JM, Proudfoot AE, Power CA, Baggiolini M, Wells TN. Functional expression of CCR1, CCR3, CCR4, and CXCR4 chemokine receptors on human platelets. Blood. (2000) 96:4046-54.

58. Fuchs TA, Bhandari AA, Wagner DD. Histones induce rapid and profound thrombocytopenia in mice. Blood. (2011) 118:3708-14. doi: 10.1182/blood-2011-01-332676

59. Wong CHY, Jenne CN, Petri B, Chrobok NL, Kubes P. Nucleation of platelets with blood-borne pathogens on Kupffer cells precedes other innate immunity and contributes to bacterial clearance. Nat Immunol. (2013) 14:785-92. doi: 10.1038/ni.2631

60. Shibazaki M, Nakamura M, Endo Y. Biphasic, organ-specific, and strainspecific accumulation of platelets induced in mice by a lipopolysaccharide from Escherichia coli and its possible involvement in shock. Infect Immun. (1996) 64:5290-4.

61. Zarbock A, Singbartl K, Ley K. Complete reversal of acid-induced acute lung injury by blocking of platelet-neutrophil aggregation. J Clin Invest. (2006) 116:3211-9. doi: 10.1172/JCI29499

62. McDonald B, Urrutia R, Yipp BG, Jenne CN, Kubes P. Intravascular neutrophil extracellular traps capture bacteria from the bloodstream during sepsis. Cell Host Microbe. (2012) 12:324-33. doi: 10.1016/j.chom.2012.06.011

63. Massberg S, Grahl L, Bruehl von M-L, Manukyan D, Pfeiler S, Goosmann C, et al. Reciprocal coupling of coagulation and innate immunity via neutrophil serine proteases. Nat Med. (2010) 16:887-96. doi: 10.1038/nm.2184

64. Birnie E, Claushuis TAM, Koh GCKW, Limmathurotsakul D, Day NPJ, Roelofs JJTH, et al. Thrombocytopenia impairs host defense against Burkholderia pseudomallei (Melioidosis). J Infect Dis. (2019) 219:648-59. doi: 10.1093/infdis/jiy541

65. Sheu JR, Hung WC, Wu CH, Ma MC, Kan YC, Lin CH, et al. Reduction in lipopolysaccharide-induced thrombocytopenia by triflavin in a rat model of septicemia. Circulation. (1999) 99:3056-62. doi: 10.1161/01.cir.99.23.3056

66. Jenne CN, Wong CHY, Petri B, Kubes P. The use of spinning-disk confocal microscopy for the intravital analysis of platelet dynamics in response to systemic and local inflammation. PLoS ONE. (2011) 6:e25109. doi: 10.1371/journal.pone.0025109

67. McDonald B, Davis RP, Kim S-J, Tse M, Esmon CT, Kolaczkowska E, et al. Platelets and neutrophil extracellular traps collaborate to promote intravascular coagulation during sepsis in mice. Blood. (2017) 129:1357-67. doi: 10.1182/blood-2016-09-741298

68. Sreeramkumar V, Adrover JM, Ballesteros I, Cuartero MI, Rossaint J, Bilbao I, et al. Neutrophils scan for activated platelets to initiate inflammation. Science. (2014) 346:1234-8. doi: 10.1126/science.1256478

69. Marshall BT, Long M, Piper JW, Yago T, McEver RP, Zhu C. Direct observation of catch bonds involving cell-adhesion molecules. Nature. (2003) 423:190-3. doi: 10.1038/nature01605

70. Sundd P, Gutierrez E, Koltsova EK, Kuwano Y, Fukuda S, Pospieszalska MK, et al. "Slings" enable neutrophil rolling at high shear. Nature. (2012) 488:399-403. doi: 10.1038/nature11248

71. Schmidtke DW, Diamond SL. Direct observation of membrane tethers formed during neutrophil attachment to platelets or P-selectin under physiological flow. J Cell Biol. (2000) 149:719-30. doi: 10.1083/jcb.149.3.719

72. Rossaint J, Kühne K, Skupski J, Van Aken H, Looney MR, Hidalgo A, et al. Directed transport of neutrophil-derived extracellular vesicles enables platelet-mediated innate immune response. Nat Commun. (2016) 7:13464. doi: $10.1038 /$ ncomms 13464

73. Evangelista V, Manarini S, Rotondo S, Martelli N, Polischuk R, McGregor JL, de Gaetano G, Cerletti C. Platelet/polymorphonuclear leukocyte interaction in dynamic conditions: evidence of adhesion cascade and cross talk between P-selectin and the beta 2 integrin CD11b/CD18. Blood. (1996) 88:4183-94.

74. Evangelista V, Pamuklar Z, Piccoli A, Manarini S, Dell'elba G, Pecce R, et al. Src family kinases mediate neutrophil adhesion to adherent platelets. Blood. (2007) 109:2461-9. doi: 10.1182/blood-2006-06-029082

75. Konstantopoulos K, Neelamegham S, Burns AR, Hentzen E, Kansas GS, Snapp KR, et al. Venous levels of shear support neutrophil-platelet adhesion and neutrophil aggregation in blood via P-selectin and beta2-integrin. Circulation. (1998) 98:873-82.

76. Hidalgo A, Chang J, Jang J-E, Peired AJ, Chiang EY, Frenette PS. Heterotypic interactions enabled by polarized neutrophil microdomains mediate thromboinflammatory injury. Nat Med. (2009) 15:384-91. doi: $10.1038 / \mathrm{nm} .1939$

77. Weber C, Springer TA. Neutrophil accumulation on activated, surfaceadherent platelets in flow is mediated by interaction of Mac-1 with fibrinogen bound to alphaIIbbeta3 and stimulated by platelet-activating factor. J Clin Invest. (1997) 100:2085-93. doi: 10.1172/JCI1 19742

78. Simon DI, Chen Z, Xu H, Li CQ, Dong JF, McIntire LV, et al. Platelet glycoprotein ibalpha is a counterreceptor for the leukocyte integrin Mac-1 (CD11b/CD18). J Exp Med. (2000) 192:193-204. doi: 10.1084/jem.192.2.193

79. Carvalho-Tavares J, Hickey MJ, Hutchison J, Michaud J, Sutcliffe IT, et al. A role for platelets and endothelial selectins in tumor necrosis factor-alphainduced leukocyte recruitment in the brain microvasculature. Circ Res. (2000) 87:1141-8. doi: 10.1161/01.res.87.12.1141

80. Slaba I, Wang J, Kolaczkowska E, McDonald B, Lee W-Y, Kubes P. Imaging the dynamic platelet-neutrophil response in sterile liver injury and repair in mice. Hepatology. (2015) 62:1593-605. doi: 10.1002/hep.28003

81. Ortiz-Muñoz G, Mallavia B, Bins A, Headley M, Krummel MF, Looney MR. Aspirin-triggered 15-epi-lipoxin A4 regulates neutrophil-platelet aggregation and attenuates acute lung injury in mice. Blood. (2014) 124:2625-34. doi: 10.1182/blood-2014-03-562876

82. Brühl von M-L, Stark K, Steinhart A, Chandraratne S, Konrad I, Lorenz $\mathrm{M}$, et al. Monocytes, neutrophils, and platelets cooperate to initiate and propagate venous thrombosis in mice in vivo. J Exp Med. (2012) 209:819-35. doi: $10.1084 /$ jem. 20112322

83. Rossaint J, Margraf A, Zarbock A. Role of platelets in leukocyte recruitment and resolution of inflammation. Front Immunol. (2018) 9:2712. doi: $10.3389 /$ fimmu.2018.02712

84. Phillipson M, Heit B, Colarusso P, Liu L, Ballantyne CM, Kubes P. Intraluminal crawling of neutrophils to emigration sites: a molecularly distinct process from adhesion in the recruitment cascade. J Exp Med. (2006) 203:2569-75. doi: 10.1084/jem.20060925

85. McDonald B, Pittman K, Menezes GB, Hirota SA, Slaba I, Waterhouse CCM, et al. Intravascular danger signals guide neutrophils to sites of sterile inflammation. Science. (2010) 330:362-6. doi: 10.1126/science.1195491

86. Kolaczkowska E, Kubes P. Neutrophil recruitment and function in health and inflammation. Nat Rev Immunol. (2013) 13:159-75. doi: 10.1038/nri3399

87. Pitchford SC, Momi S, Baglioni S, Casali L, Giannini S, Rossi R, et al. Allergen induces the migration of platelets to lung tissue in allergic asthma. Am J Respir Crit Care Med. (2008) 177:604-12. doi: 10.1164/rccm.200702-214OC

88. Gaertner F, Ahmad Z, Rosenberger G, Fan S, Nicolai L, Busch B, et al. Migrating platelets are mechano-scavengers that collect and bundle bacteria. Cell. (2017) 171:1368-82.e23. doi: 10.1016/j.cell.2017.11.001

89. Kraemer BF, Campbell RA, Schwertz H, Cody MJ, Franks Z, Tolley ND, et al. Novel anti-bacterial activities of $\beta$-defensin 1 in human platelets: suppression of pathogen growth and signaling of neutrophil extracellular trap formation. PLoS Pathog. (2011) 7:e1002355. doi: 10.1371/journal.ppat.1002355

90. Drago L, Bortolin M, Vassena C, Taschieri S, Del Fabbro M. Antimicrobial activity of pure platelet-rich plasma against microorganisms isolated from oral cavity. BMC Microbiol. (2013) 13:47. doi: 10.1186/1471-2180-13-47

91. Ali RA, Wuescher LM, Dona KR, Worth RG. Platelets mediate host defense against Staphylococcus aureus through direct bactericidal activity and by enhancing macrophage activities. J Immunol. (2017) 198:344-51. doi: $10.4049 /$ jimmunol.1601178 
92. Youssefian T, Drouin A, Massé J-M, Guichard J, Cramer EM. Host defense role of platelets: engulfment of HIV and Staphylococcus aureus occurs in a specific subcellular compartment and is enhanced by platelet activation. Blood. (2002) 99:4021-9. doi: 10.1182/blood-2001-12-0191

93. Assinger A, Laky M, Schabbauer G, Hirschl AM, Buchberger E, Binder BR, et al. Efficient phagocytosis of periodontopathogens by neutrophils requires plasma factors, platelets and TLR2. J Thromb Haemost. (2011) 9:799-809. doi: 10.1111/j.1538-7836.2011.04193.x

94. Miyabe K, Sakamoto N, Wu YH, Mori N, Sakamoto H. Effects of platelet release products on neutrophilic phagocytosis and complement receptors. Thromb Res. (2004) 114:29-36. doi: 10.1016/j.thromres.2004.04.003

95. Suzuki K, Sugimura K, Hasegawa K, Yoshida K, Suzuki A, Ishizuka K, et al. Activated platelets in ulcerative colitis enhance the production of reactive oxygen species by polymorphonuclear leukocytes. Scand J Gastroenterol. (2001) 36:1301-6. doi: 10.1080/003655201317 097164

96. Evangelista V, Manarini S, Dell'elba G, Martelli N, Napoleone E, Di Santo A, Lorenzet PSR. Clopidogrel inhibits platelet-leukocyte adhesion and platelet-dependent leukocyte activation. Thromb Haemost. (2005) 94:568-77. doi: 10.1160/th05-01-0020

97. Brinkmann V, Reichard U, Goosmann C, Fauler B, Uhlemann Y, Weiss DS, et al. Neutrophil extracellular traps kill bacteria. Science. (2004) 303:1532-5. doi: $10.1126 /$ science. 1092385

98. Papayannopoulos V. Neutrophil extracellular traps in immunity and disease. Nat Rev Immunol. (2018) 18:134-47. doi: 10.1038/nri.2017.105

99. Jenne CN, Wong CHY, Zemp FJ, McDonald B, Rahman MM, Forsyth PA, et al. Neutrophils recruited to sites of infection protect from virus challenge by releasing neutrophil extracellular traps. Cell Host Microbe. (2013) 13:16980. doi: 10.1016/j.chom.2013.01.005

100. Rossaint J, Herter JM, Van Aken H, Napirei M, Döring Y, Weber C, et al. Synchronized integrin engagement and chemokine activation is crucial in neutrophil extracellular trap-mediated sterile inflammation. Blood. (2014) 123:2573-84. doi: 10.1182/blood-2013-07-516484

101. Caudrillier A, Kessenbrock K, Gilliss BM, Nguyen JX, Marques MB, Monestier $\mathrm{M}$, et al. Platelets induce neutrophil extracellular traps in transfusion-related acute lung injury. J Clin Invest. (2012) 122:2661-71. doi: 10.1172/JCI61303

102. Rondina MT, Carlisle M, Fraughton T, Brown SM, Miller RR, Harris ES, et al. Platelet-monocyte aggregate formation and mortality risk in older patients with severe sepsis and septic shock. J Gerontol A Biol Sci Med Sci. (2015) 70:225-31. doi: 10.1093/gerona/glu082

103. Tunjungputri RN, van de Heijden W, Urbanus RT, de Groot PG, van der Ven A, de Mast Q. Higher platelet reactivity and plateletmonocyte complex formation in Gram-positive sepsis compared to Gramnegative sepsis. Platelets. (2017) 28:595-601. doi: 10.1080/09537104.2016.1 252837

104. Goncalves R, Zhang X, Cohen H, Debrabant A, Mosser DM. Platelet activation attracts a subpopulation of effector monocytes to sites of Leishmania major infection. J Exp Med. (2011) 208:1253-65. doi: 10.1084/jem.20101751

105. Hottz ED, Medeiros-de-Moraes IM, Vieira-de-Abreu A, de Assis EF, Valsde-Souza R, Castro-Faria-Neto HC, et al. Platelet activation and apoptosis modulate monocyte inflammatory responses in dengue. J Immunol. (2014) 193:1864-72. doi: 10.4049/jimmunol.1400091

106. Carestia A, Mena HA, Olexen CM, Ortiz Wilczyñski JM, Negrotto S, Errasti AE, et al. Platelets promote macrophage polarization toward proinflammatory phenotype and increase survival of septic mice. Cell Rep. (2019) 28:896-908.e5. doi: 10.1016/j.celrep.2019.06.062

107. Xiang B, Zhang G, Guo L, Li X-A, Morris AJ, Daugherty A, et al. Platelets protect from septic shock by inhibiting macrophage-dependent inflammation via the cyclooxygenase 1 signalling pathway. Nat Commun. (2013) 4:2657. doi: 10.1038/ncomms3657

108. Colón DF, Wanderley CW, Franchin M, Silva CM, Hiroki CH, Castanheira FVS, et al. Neutrophil extracellular traps (NETs) exacerbate severity of infant sepsis. Critical Care. (2019) 23:113. doi: 10.1186/s13054-019-2407-8

109. Lefrançais E, Mallavia B, Zhuo H, Calfee CS, Looney MR. Maladaptive role of neutrophil extracellular traps in pathogen-induced lung injury. JCI Insight. (2018) 3:98178. doi: 10.1172/jci.insight.98178
110. Mai SHC, Khan M, Dwivedi DJ, Ross CA, Zhou J, Gould TJ, et al. Delayed but not early treatment with DNase reduces organ damage and improves outcome in a murine model of sepsis. Shock. (2015) 44:166-72. doi: 10.1097/SHK.0000000000 000396

111. Biron BM, Chung C-S, Chen Y, Wilson Z, Fallon EA, Reichner JS, et al. PAD4 Deficiency leads to decreased organ dysfunction and improved survival in a dual insult model of hemorrhagic shock and sepsis. J Immunol. (2018) 200:1817-28. doi: 10.4049/jimmunol.1700639

112. Jiménez-Alcázar M, Rangaswamy C, Panda R, Bitterling J, Simsek YJ, Long AT, et al. Host DNases prevent vascular occlusion by neutrophil extracellular traps. Science. (2017) 358:1202-6. doi: 10.1126/science.aam8897

113. Czaikoski PG, Mota JMSC, Nascimento DC, Sônego F, Castanheira FVES, Melo PH, et al. Neutrophil extracellular traps induce organ damage during experimental and clinical sepsis. PLoS ONE. (2016) 11:e0148142. doi: 10.1371/journal.pone.0148142

114. Martinod K, Fuchs TA, Zitomersky NL, Wong SL, Demers M, Gallant $\mathrm{M}$, et al. PAD4-deficiency does not affect bacteremia in polymicrobial sepsis and ameliorates endotoxemic shock. Blood. (2015) 125:1948-56. doi: 10.1182/blood-2014-07-587709

115. Kolaczkowska E, Jenne CN, Surewaard BGJ, Thanabalasuriar A, Lee W-Y, Sanz M-J, Mowen K, Opdenakker G, Kubes P. Molecular mechanisms of NET formation and degradation revealed by intravital imaging in the liver vasculature. Nat Commun. (2015) 6:6673. doi: 10.1038/ncomms7673

116. Xu J, Zhang X, Pelayo R, Monestier M, Ammollo CT, Semeraro F, et al. Extracellular histones are major mediators of death in sepsis. Nat Med. (2009) 15:1318-21. doi: 10.1038/nm.2053

117. Yang S, Qi H, Kan K, Chen J, Xie H, Guo X, Zhang L. Neutrophil extracellular traps promote hypercoagulability in patients with sepsis. Shock. (2017) 47:132-9. doi: 10.1097/SHK.0000000000000741

118. Delabranche X, Stiel L, Severac F, Galoisy A-C, Mauvieux L, Zobairi F, et al. Evidence of netosis in septic shock-induced disseminated intravascular coagulation. Shock. (2017) 47:313-7. doi: 10.1097/SHK.0000000000 000719

119. Abrams ST, Morton B, Alhamdi Y, Alsabani M, Lane S, Welters ID, et al. A Novel Assay for Neutrophil Extracellular Traps (NETs) formation independently predicts disseminated intravascular coagulation and mortality in critically Ill patients. Am J Respir Crit Care Med. (2019) 200:869-80. doi: 10.1164/rccm.201811-21110C

120. Semeraro F, Ammollo CT, Morrissey JH, Dale GL, Friese P, Esmon NL, et al. Extracellular histones promote thrombin generation through plateletdependent mechanisms: involvement of platelet TLR2 and TLR4. Blood. (2011) 118:1952-61. doi: 10.1182/blood-2011-03-343061

121. Sambrano GR, Huang W, Faruqi T, Mahrus S, Craik C, Coughlin SR. Cathepsin $\mathrm{G}$ activates protease-activated receptor-4 in human platelets. J Biol Chem. (2000) 275:6819-23. doi: 10.1074/jbc.275.10.6819

122. Wang Y, Luo L, Braun OÖ, Westman J, Madhi R, Herwald H, et al. Neutrophil extracellular trap-microparticle complexes enhance thrombin generation via the intrinsic pathway of coagulation in mice. Sci Rep. (2018) 8:4020. doi: 10.1038/s41598-018-22156-5

123. Folco EJ, Mawson TL, Vromman A, Bernardes-Souza B, Franck G, Persson $\mathrm{O}$, et al. Neutrophil extracellular traps induce endothelial cell activation and tissue factor production through interleukin-1 $\alpha$ and cathepsin G. Arterioscler Thromb Vasc Biol. (2018) 38:1901-12. doi: 10.1161/ATVBAHA.118.311150

124. Fuchs TA, Brill A, Duerschmied D, Schatzberg D, Monestier M, Myers DD, et al. Extracellular DNA traps promote thrombosis. Proc Natl Acad Sci USA. (2010) 107:15880-5. doi: 10.1073/pnas.1005743107

125. Döring Y, Soehnlein O, Weber C. Neutrophil extracellular traps in atherosclerosis and atherothrombosis. Circ Res. (2017) 120:736-43. doi: 10.1161/CIRCRESAHA.116.309692

126. Palm F, Sjöholm K, Malmström J, Shannon O. Complement activation occurs at the surface of platelets activated by streptococcal M1 protein and this results in phagocytosis of platelets. J Immunol. (2019) 202:503-13. doi: 10.4049/jimmunol.1800897

127. Nording H, Langer HF. Complement links platelets to innate immunity. Semin Immunol. (2018) 37:43-52. doi: 10.1016/j.smim.2018.01.003

128. Chen W, Janz DR, Bastarache JA, May AK, O’Neal HR, Bernard GR, et al. Prehospital aspirin use is associated with reduced risk of acute 
respiratory distress syndrome in critically ill patients: a propensity-adjusted analysis. Crit Care Med. (2015) 43:801-7. doi: 10.1097/CCM.0000000000 000789

129. Eisen DP, Reid D, McBryde ES. Acetyl salicylic acid usage and mortality in critically ill patients with the systemic inflammatory response syndrome and sepsis. Crit Care Med. (2012) 40:1761-7. doi: 10.1097/CCM.0b013e318246b9df

130. Winning J, Neumann J, Kohl M, Claus RA, Reinhart K, Bauer M, et al. Antiplatelet drugs and outcome in mixed admissions to an intensive care unit. Crit Care Med. (2010) 38:32-7. doi: 10.1097/CCM.0b013e3181b4275c

131. Eisen DP, Moore EM, Leder K, Lockery J, McBryde ES, et al. AspiriN To Inhibit SEPSIS (ANTISEPSIS) randomised controlled trial protocol. BMJ Open. (2017) 7:e013636. doi: 10.1136/bmjopen-2016-013636
Conflict of Interest: The authors declare that the research was conducted in the absence of any commercial or financial relationships that could be construed as a potential conflict of interest.

The handling Editor declared a shared affiliation, though no other collaboration, with the authors at time of review.

Copyright (c) 2019 McDonald and Dunbar. This is an open-access article distributed under the terms of the Creative Commons Attribution License (CC BY). The use, distribution or reproduction in other forums is permitted, provided the original author(s) and the copyright owner(s) are credited and that the original publication in this journal is cited, in accordance with accepted academic practice. No use, distribution or reproduction is permitted which does not comply with these terms. 